\title{
Microscopic colitis: A literature review
}

\author{
Ana Paula Hamer Sousa Clara ${ }^{1}$, Flávia Drago Magnago ${ }^{2}$, Juliana Neves Ferreira ${ }^{2}$, Thais Gagno Grillo ${ }^{2 *}$ \\ ${ }^{1}$ MSc in Public Policies and Local Development from Escola Superior de Ciências da Santa Casa de Misericórdia de Vitória (Emescam). Professor of Semiology and Internal Medicine at Emescam, Vitória, ES, Brazi \\ ${ }^{2} \mathrm{MD}$ from Emescam, Vitória, ES, Brazil
}

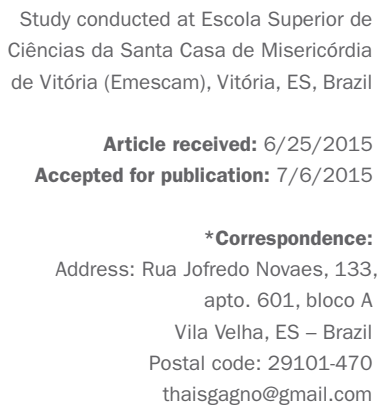

http://dx.doi.org/10.1590/1806-9282.62.09.895

\section{SUMMARY}

Microscopic colitis (MC) refers to chronic inflammation of the colon which is characterized by histologic changes at the level of a radiologically and endoscopically normal mucosa. It is a common cause of chronic non-bloody diarrhea that occurs primarily in older individuals; however, there are few studies in the literature with strong scientific evidence compared to other inflammatory bowel diseases (IBD), which limits the knowledge of physicians and pathologists. This article aims to review the information on $\mathrm{MC}$, describing diagnostic methods and drugs available for treatment. We conducted a search of the Pubmed database and CAPES Portal using the keywords "microscopic colitis", "collagenous colitis", "lymphocytic colitis", and "review" for selection of articles published between 1996 and 2015 related to the topic. Based on the studies discussed in this review, we conclude that MC is a relatively new gastrointestinal disorder, most studies are incipient particularly with respect to pathophysiology and immunology, and budesonide is the best documented short-term treatment. However, further studies are needed to elucidate the best strategy for treatment in the long term.

Keywords: microscopic colitis, collagenous colitis, lymphocytic colitis, review.

\section{INTRODUCTION}

Microscopic colitis (MC) refers to chronic inflammation of the colon which is characterized by histologic changes at the level of a radiologically and endoscopically normal mucosa. It is a common cause of chronic non-bloody diarrhea that occurs primarily in older individuals, accounting for 10 to $20 \%$ of cases. ${ }^{1}$

Collagenous colitis (CC) was described in 1976 by Lindstrom and Freeman with clinical and histological features similar to MC, except for the presence of a thick band of subepithelial collagen. The term MC was used in 1980 to describe patients with chronic watery diarrhea and normal findings on sigmoidoscopy and barium enema but with microscopic inflammation on colon biopsy. It is unclear whether these two conditions represent separate diseases or are phenotypes of the same disease. ${ }^{2}$

Currently, MC includes two subsets: CC, with a thick band of subepithelial collagen, and lymphocytic colitis (LC), without collagen thickening and with an increase in the number of intraepithelial lymphocytes $(\geq 20 / 100$ epithelial cells). ${ }^{2,3}$

\section{Method}

The literature review was adopted for the preparation of this article on MC. Data was collected from articles published between 1996 and 2015 in journals indexed in the Pubmed and CAPES Portal search engines. The keywords used were "microscopic colitis", "collagenous colitis", "lymphocytic colitis" and "review" for the selection of articles related to the topic. The search included original articles and literature reviews published in English. The research was also complemented by articles referenced in other publications already selected. The investigation was only concluded when signs of theoretical saturation of the research topic emerged.

\section{EPIDEMIOLOGY}

Several risk factors have been described for MC, the main ones including: female, advanced age, autoimmune dis- 
eases, past or current diagnosis of malignancy and history of solid organ transplants. ${ }^{3}$

Recent studies in the US have shown an MC incidence rate of 7.1 per 100,000 individuals/year for CC, and 12.6 per 100,000 individuals/year for LC. ${ }^{4}$ The global prevalence of MC was observed at 103.0 per 100,000 individuals, with 39.3 per 100,000 individuals for CC and 63.7 per 100,000 individuals for LC. These figures are similar to the data obtained for classic inflammatory bowel diseases (IBD). ${ }^{3}$

$\mathrm{MC}$ is typically a disease of the elderly, with an average age at diagnosis of 65 years. ${ }^{5} \mathrm{CC}$ is around 20 times more frequent in women, while LC is equally distributed between men and women. ${ }^{4} \mathrm{MC}$ is a rare phenomenon in children and $25 \%$ of patients with MC are aged less than 45 years, which reflects the need for investigation in young patients with chronic diarrhea. ${ }^{5}$

\section{Pathogenesis}

The pathophysiology of MC is still unknown, but it is believed that it is due to a multifactorial etiology, involving an exacerbated immune response to harmful luminal agents in the mucosa of these individuals. ${ }^{1,3,4}$

There is strong evidence of an autoimmune basis for CC and LC, both of which are associated with diseases such as celiac disease (12\%), thyroid diseases (10.3\%), Sjögren's syndrome (3.4\%) and diabetes mellitus (1.7\%). ${ }^{3-5}$ Various autoantibodies and phenotypes can be found along with $\mathrm{MC}$, including the DR3 phenotype of human leukocyte antigen (HLA). However, no specific autoantibody has been identified as relevant in the diagnosis., ${ }^{3,4}$

Several luminal factors have an important role in the pathogenesis of MC. Many drugs are cited, such as aspirin, nonsteroidal anti-inflammatory drugs (NSAIDs), proton pump inhibitors (PPIs), sertraline, ranitidine, simvastatin, carbamazepine, and more. These medications should be stopped when MC is diagnosed, which may result in improvement of the symptoms reported by the patient.,

Malabsorption of bile acids was found in up to $60 \%$ of patients with LC and $44 \%$ of patients with CC, supporting the idea that this may be the cause of MC. ${ }^{3,4}$ Increases were also reported in interferon gamma (IFN- $\gamma$ ), tumor necrosis factor alpha (TNF- $\alpha$ ), interleukin 1 beta (IL-1 $\beta$ ), and a profile of Th1 cytokines, which are suggested to be involved in the inflammatory process. ${ }^{3,4}$

As for environmental factors, the major etiologic role is played by cigarettes. Smoking is more prevalent among patients with MC, and studies indicate an association with lung cancer. It has also been demonstrated that MC involvement in individuals that smoke occurs around 10 years earlier, increasing the relevance of this habit. ${ }^{3-5}$

\section{Clinical presentation}

LC and CC are not distinguishable from each other based on symptoms and clinical presentation. Differentiation between the two is undertaken through histology only. 1,3,4,6

The main symptom noted is chronic, typically aqueous, non-bloody diarrhea; nocturnal diarrhea is common (50\%), as well as urgency $(70 \%)$ and fecal incontinence $(40 \%)^{1,3-10}$

Abdominal pain is a common symptom and may be present in up to $50 \%$ of patients. A differential diagnosis with irritable bowel syndrome (IBS) should therefore be investigated. ${ }^{1,3,5,6}$ Weight loss is also observed during active disease in almost half of patients. Celiac disease should be investigated and discarded in patients with marked weight loss, steatorrhea, iron deficiency anemia, and those who do not respond to the usual therapy. ${ }^{1,5}$

The presence of fever, vomiting, or hematochezia should indicate the possibility of an alternative diagnosis. ${ }^{8}$

\section{LABORATORY AND IMAGING DIAGNOSIS}

The diagnosis of MC depends on a proper medical history, with the exclusion of other diseases, normal radiological/endoscopic findings and endoscopic biopsies with histopathological findings consistent with MC. ${ }^{4}$

Medical history helps to rule out other etiologies that can cause a similar clinical presentation, such as IBD, celiac disease and IBS. Laboratory and radiographic examinations also rule out other pathologies, but are typically normal. ${ }^{4}$ Only non-specific changes may be found, such as moderately high C-reactive protein and anemia. A stool examination usually reveals the absence of pathological microorganisms. The diagnostic accuracy of calprotectin and fecal lactoferrin is low. ${ }^{11}$

Barium enema and colonoscopy are usually normal, although subtle changes may be observed in the mucosa, such as edema, enanthem and abnormal vascular pattern, occasionally seen during colonoscopy. ${ }^{12}$

\section{Histological diagnosis}

The diagnosis of MC is based solely on results of typical microscopic changes in mucosal biopsies of the colon. In CC (Figure 1) we can observe thickening of the subepithelial collagen layer together with chronic mononuclear inflammation in the lamina propria and damaged epithelial cells with an occasional increase in the number of intraepithelial lymphocytes. The enlargement of the subepithelial collagen layer is greater than $10 \mu \mathrm{m}$, in contrast with the normal basal membrane which measures less than $3 \mu \mathrm{m} .{ }^{13}$

The thickening of the collagen layer can vary and is most prominent in the ascending and transverse colon; it 


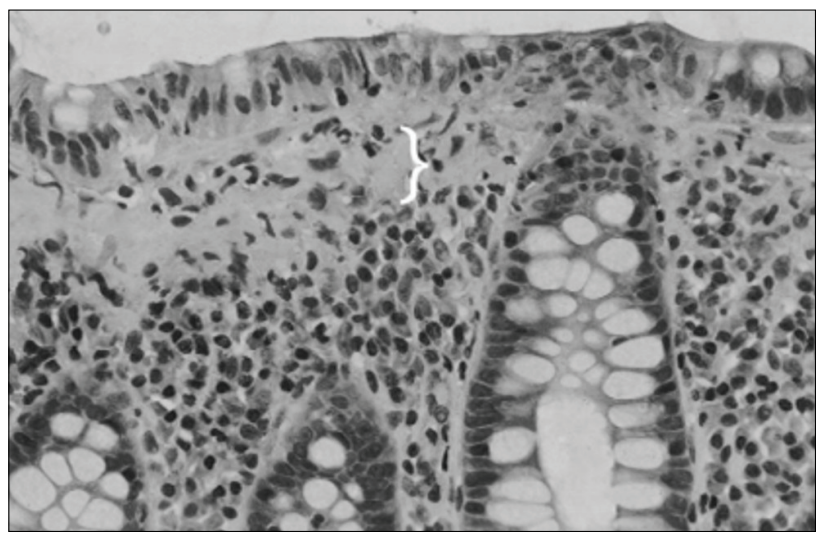

FIGURE 1 Collagenous colitis. In addition to the inflammatory infiltrate, a thick band of subepithelial collagen can be observed (brace).

Source: adapted from Pardi DS et al. ${ }^{2}$

may be absent in biopsies of the sigmoid colon or rectum, emphasizing the importance of obtaining proximal colon biopsies for the diagnosis of CC. In general, histopathological changes are restricted to the large intestine, although thickening of the collagen layer may infrequently be found in the stomach, duodenum or terminal ileum. ${ }^{13}$

Meanwhile, in LC (Figure 2), we can observe an increase in the number of intraepithelial lymphocytes $(\geq$ 20/100 surface epithelial cells), in conjunction with damage to the surface of the epithelial cells and infiltration of lymphocytes and plasma cells in the lamina propria. The collagen layer, however, remains normal. In doubtful cases, immunolabeling of CD3 T lymphocytes facilitates the assessment of the amount of intraepithelial lymphocytes. ${ }^{3,13}$

There are histological similarities between the two forms of colitis, such as inflammation in the lamina propria essentially consisting of an increase in the number of lymphocytes and plasma cells and epithelial damage. ${ }^{4}$

\section{TREATMENT}

The first step in treating patients with MC is to search for exacerbating factors, such as dietary history in order to search for foods that contribute to cause diarrhea, such as dairy products in patients with lactose intolerance or excessive consumption of dietetic products like caffeine and alcohol. ${ }^{1,2,13,14}$

It is also important to review the medication currently used by the patient in order to search for drugs or substances that are causing or exacerbating the diarrhea in MC. ${ }^{1,5,8,14}$ Stopping smoking should be considered, although the evidence for such is still weak. ${ }^{5}$ Nevertheless, most patients with $\mathrm{MC}$ require treatment. ${ }^{1}$
Treatment of MC must take into account the severity of the symptoms, the impact on the patient's quality of life and the availability of data about the results of randomized clinical trials. The main objective is to achieve clinical remission and improve the patient's quality of life. It is not currently known whether histological remission is relevant to the recurrence rate. Therefore, it is unclear if this should be an important goal. ${ }^{7}$

Antidiarrheal drugs such as loperamide are often used in MC empirically in patients with mild diarrhea, but have never been formally tested in randomized placebo controlled trials. Clinical remission is rarely achieved and an impact on colon inflammation is unlikely. ${ }^{1,5,7}$

In 1998, Fine et al. ${ }^{15}$ suggested the use of three bismuth subsalicylate tablets $(262 \mathrm{mg} /$ each), three times/ day in patients with mild symptoms or those that do not respond to loperamide. However, in 2001, Pardi et al. ${ }^{16}$ showed that most patients treated with this medication showed a partial response.

Steroids are the most effective treatment in patients with more intense symptoms and nonresponders to bismuth, with the use of budesonide as the best-documented treatment. ${ }^{1,9}$

Baert et al., ${ }^{17}$ Bonderup et al. ${ }^{18}$ and Miehlke et al. ${ }^{19}$ showed the efficacy of budesonide at a dose of $9 \mathrm{mg} /$ day for 6 to 8 weeks for the induction of clinical remission in randomized placebo-controlled clinical trials on CC. Most patients responded quickly to budesonide, and presented a substantial improvement in quality of life and clinical symptoms after 2 to 4 weeks of treatment. In a Cochrane meta-analysis conducted in 2009 by Chande et

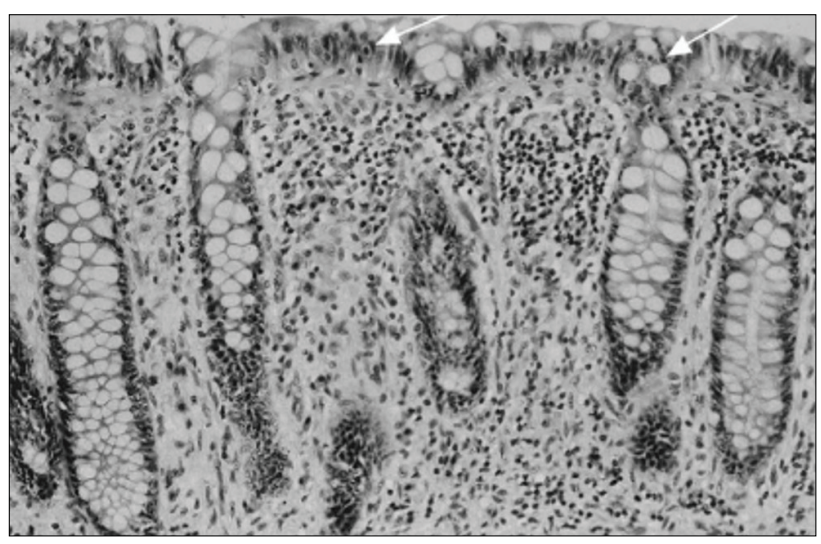

FIGURE 2 Lymphocytic colitis. Intraepithelial lymphocytosis (arrows) can be observed, and mixed inflammatory infiltrate in the lamina propria. With regard to the distinction between ulcerative colitis and Crohn's colitis, the architecture of the crypts is normal. Source: adapted from Pardi DS et al. ${ }^{2}$ 
al. ${ }^{20}$ the odds ratio for clinical response to budesonide compared to a placebo was 12.32 (95CI 5.53-27.46), with an $81 \%$ response rate.

The same efficacy of budesonide at the dose of $9 \mathrm{mg} /$ day has been demonstrated in the treatment of LC by two placebo-controlled studies conducted in 2009 by Miehlke et al. ${ }^{21}$ and Pardi et al. ${ }^{22}$ Both studies also showed substantial improvement in colon inflammation. ${ }^{21,22}$ Two other randomized placebo-controlled trials conducted by Bonderup et al. ${ }^{23}$ and Miehlke et al. ${ }^{24}$ showed that clinical remission and histological response could be maintained in most patients with budesonide at a dose of 6 $\mathrm{mg} /$ day for 6 months, with an $83 \%$ response rate.

After stopping treatment with budesonide, relapse of symptoms may occur in 60 to $80 \%$ of patients, most of which respond to retreatment. ${ }^{1,5,7,9,25}$ Many patients therefore become steroid-dependent. As such, before starting budesonide, the diagnosis should be reviewed and differential diagnoses ruled out, such as celiac disease and hyperthyroidism. ${ }^{1,2}$

Patients treated with long-term budesonide should be monitored for side effects associated with the use of steroids, such as hypertension, hyperglycemia and changes in bone metabolism, among other factors. Furthermore, they should avoid consuming grapes, grape juice and any other cytochrome P450 inhibitors that interfere with the metabolism of budesonide and predispose to side effects. ${ }^{1}$

The main advantage of budesonide in relation to conventional corticosteroids is its limited systemic absorption, which leads to better long-term tolerance. ${ }^{25}$ Furthermore, it presents fewer side effects than prednisone, with higher efficacy demonstrated in 2013 by Gentile et al. ${ }^{26}$ in an uncontrolled study. Therefore, unless cost is a major concern, budesonide is generally used when corticotherapy is required. ${ }^{1}$

Prednisolone has been analyzed in retrospective studies conducted by Olesen et al., ${ }^{27}$ Bohr et al. ${ }^{28}$ and Pardi et al. ${ }^{29}$ and in a randomized placebo-controlled trial carried out by Munck et al. ${ }^{30}$ In the comparison, patients using budesonide showed lower recurrence than those treated with prednisolone. Therefore, prednisolone does not appear to be of value in the treatment of patients who do not respond to budesonide. ${ }^{5}$

Sulfasalazine or mesalazine have been widely used in MC, but have not been strictly evaluated in randomized placebo-controlled trials. ${ }^{9}$ In the treatment of MC, mesalazine has mainly been reported in retrospective studies carried out in 1996 by Bohr et al. ${ }^{28}$ and in 2004 by Olesen et al., ${ }^{27}$ suggesting a therapeutic response in about half of patients. In 2008, Chande et al..$^{31}$ conducted an uncontrolled prospective study that showed greater efficacy of mesalazine when administered over a period of 6 months. Due to the lack of control groups, the true value of the use of mesalazine when treating MC remains inconclusive. ${ }^{7,32}$

Calabrese et al. ${ }^{33}$ conducted a randomized study with 23 patients with CC and 41 with LC who received $2.4 \mathrm{~g} /$ day of mesalazine monotherapy, or in combination with $4 \mathrm{~g} /$ day of cholestyramine for 6 months. Disease remission was noted in $91 \%$ of the patients with CC and $85 \%$ of the patients with LC after 6 months of treatment. Combined therapy presented the best responses.

Immunosuppressive therapies, such as azathioprine, 6-mercaptopurine or methotrexate, may be useful in steroid-dependent or steroid-refractory patients. $1,5,7-9,14$

There are only a few reports of the use of anti-TNF (tumor necrosis factor inhibitors) agents in patients with $\mathrm{CC}$ at similar doses to those for IBD. However, a risk-benefit analysis should be completed, and regular monitoring is necessary. ${ }^{5}$

Probiotics Lactobacillus acidophilus LA-5 and Bifidobacterium animalis subsp. lactis BB12 (AB-Cap-10) did not show any benefit over the placebo with regard to clinical response, histological improvement or quality of life when administered for 12 weeks. ${ }^{34}$

Pentoxifylline, verapamil and subcutaneous octreotide could be treatment options, but their use has not yet been recommended..$^{14}$ Metronidazole and erythromycin may be beneficial in some patients, although diarrhea may occur again when the medication is withdrawn. ${ }^{2,9}$

Surgical intervention in patients with MC should be considered as a last resort in cases refractory to all interventions. Ileostomy with or without colectomy or ileal pouch-anal anastomosis have been successfully performed in some cases. ${ }^{1,2,5,7-9}$

\section{Prognosis}

The natural history of MC is benign and variable, with many self-limited cases. However, patients can be severely affected. It is possible to have periods of spontaneous remission and relapse, as well as an ongoing pattern. ${ }^{4}$

Some cases of MC have been reported as progressing into Crohn's disease or ulcerative colitis, but there are still no studies to demonstrate such involvement. ${ }^{4}$ The risk of cancer and mortality is similar to that of the population. ${ }^{5}$

The long-term prognosis of $\mathrm{MC}$ is generally good. In a follow-up study on CC conducted by Goff et al., ${ }^{35} 63 \%$ of patients remained in remission after 3.5 years. Meanwhile, in another cohort study conducted by Bonner et 
al., ${ }^{36}$ all 25 patients showed improvement after 47 months of diagnosis, with $29 \%$ requiring continuous medication.

\section{Final Considerations}

$\mathrm{MC}$ is a common, relatively new and under-diagnosed cause of chronic watery diarrhea, which may be confused with IBS, celiac disease, IBD and other disorders. The peak incidence occurs in middle-aged women and it is usually associated with other autoimmune disorders. Diagnosis is based on histopathological analysis of colonic mucosal biopsies, which should always be obtained in the investigation of chronic diarrhea.

The choice of initial drug therapy depends on the intensity of the patient's symptoms. In patients with mild symptoms, treatment can be attempted with antidiarrheal medications and bismuth subsalicylate. However, steroid or immunosuppressive drugs are necessary in refractory cases and those with more intense symptoms, with budesonide as the drug of choice for short-term treatment. Surgical intervention is the latest treatment option in cases refractory to all medical therapies. The prognosis is good and the disease does not increase the risk of occurrence of colorectal cancer.

It is necessary to take a multidisciplinary and individualized approach, always considering MC as a possible diagnosis in patients who present chronic diarrhea.

We conclude that there is a need for further randomized placebo-controlled studies, especially with regard to immunomodulators and anti-TNF drugs, as experience with such is still limited, in order to provide better long-term therapeutic strategies and, consequently, better clinical management of the patient.

\section{Resumo}

Colite microscópica: uma revisão da literatura

Colite microscópica $(\mathrm{CM})$ corresponde à inflamação crônica do cólon que se manifesta por modificações histológicas em nível de uma mucosa radiológica e endoscopicamente normal. É uma causa comum de diarreia crônica não sanguinolenta que ocorre principalmente em indivíduos idosos; porém, há poucos trabalhos na literatura com forte evidência científica quando comparada à de outras doenças inflamatórias intestinais (DII), o que limita seu conhecimento por médicos e patologistas. Este artigo tem como objetivo revisar as informações referentes à $\mathrm{CM}$ descrevendo os meios diagnósticos e os medicamentos disponíveis para o tratamento. Foi realizada uma pesquisa na base de dados Pubmed e no Portal da
CAPES entre 1996 e 2015 utilizando as palavras-chave "colite microscópica", "colite colagenosa", "colite linfocítica" e "revisão" para seleção de artigos relacionados ao tema. Diante dos trabalhos analisados, conclui-se que a CM é uma desordem gastrointestinal relativamente nova, a maioria dos estudos são incipientes, principalmente quanto à imunologia e fisiopatologia, e a budesonida é o tratamento em curto prazo mais bem documentado. Todavia são necessários novos estudos para elucidar qual é a melhor estratégia em longo prazo.

Palavras-chave: colite microscópica, colite colagenosa, colite linfocítica, revisão.

\section{REFERENCES}

1. Pardi DS. Microscopic colitis. Clin Geriatr Med. 2014; 30(1):55-65.

2. Pardi DS, Smyrk TC, Tremaine WJ, Sandborn, WJ. Microscopic colitis: a review. Am J Gastroenterol. 2002; 97(4):794-802.

3. Storr MA. Microscopic colitis: epidemiology, pathophysiology, diagnosis and current management: an update. ISRN Gastroenterol. 2013; 2013:352718.

4. Ingle SB, Adgaonkar BD, Ingle CR. Microscopic colitis: common cause of unexplained nonbloody diarrhea. World J Gastrointest Pathophysiol. 2014; $5(1): 48-53$.

5. Münch A, Langner C. Microscopic colitis: clinical and pathologic perspectives. Clin Gastroenterol Hepatol. 2015; 13(2):228-36.

6. Fernández-Bañares F, Salas A, Esteve M. Pitfalls and errors in the diagnosis of collagenous and lymphocytic colitis. J Crohns Colitis. 2008; 2(4):343-7.

7. Münch A, Aust D, Bohr J, Bonderup O, Fernández- Bañares F, Hjortswang $\mathrm{H}$, et al. Microscopic colitis: current status, present and future challenges: Statements of the European Microscopic Colitis Group. J Crohns Colitis. 2012; 6(9):932-45.

8. Brown WR, Tayal S. Microscopic colitis: a review. J Dig Dis. 2013; 14(6):277-81.

9. Nyhlin N, Bohr J, Eriksson S, Tysk C. Microscopic colitis: a common and an easily overlooked cause of chronic diarrhea. Eur J Intern Med. 2008; 19(3):181-6.

10. Treanor D, Sheahan K. Microscopic colitis: lymphocytic and collagenous colitis. Curr Diagn Pathol. 2002; 8(1):33-41.

11. Wildt S, Nordgaard-Lassen I, Bendtsen F, Rumessen JJ. Metabolic and inflammatory faecal markers in collagenous colitis. Eur J Gastroenterol Hepatol. 2007; 19(7):567-74.

12. Kiesslich, R, Hoffman A, Goetz M, Biesterfeld S, Vieth M, Galle PR, et al. In vivo diagnosis of collagenous colitis by confocal endomicroscopy. Gut. 2006; 55(4):591-2.

13. Tysk C, Bohr J, Nyhlin N, Wickbom A, Eriksson S. Diagnosis and management of microscopic colitis. World J Gastroenterol. 2008; 14(48):7280-8.

14. Williams JJ, Beck PL, Andrews CN, Hogan DB, Storr MA. Microscopic colitis: a common cause of diarrhea in older adults. Age Ageing. 2010; 39(2):162-8.

15. Fine KD, Lee EL. Efficacy of open-label bismuth subsalicylate for the treatment of microscopic colitis. Gastroenterology. 1998; 114(1):29-36.

16. Pardi DS, Ramnath VR, Loftus EV, Tremaine WJ, Sandborn WJ. Treatment outcomes in lymphocytic colitis. Gastroenterology. 2001; 120(5):A13.

17. Baert F, Schmit A, D’Haens G, Dedeurwaerdere F, Louis E, Cabooter M, et al. Budesonide in collagenous colitis: a double-blind placebo-controlled trial with histologic follow-up. Gastroenterology. 2002; 122(1):20-5.

18. Bonderup OK, Hansen JB, Birket-Smith L, Vestergaard V, Teglbjaerg PS, Fallingborg J. Budesonide treatment of collagenous colitis: a randomised, double blind, placebo controlled trial with morphometric analysis. Gut. 2003; 52(2):248-51.

19. Miehlke S, Heymer P, Bethke B, Bästlein E, Meier E, Bartram HP, et al. Budesonide treatment for collagenous colitis: a randomized, double-blind, placebo-controlled, multicenter trial. Gastroenterology. 2002; 123(4):978-84.

20. Chande N, MacDonald JK, McDonald JW. Interventions for treating microscopic colitis: a Cochrane Inflammatory Bowel Disease and Functional Bowel Disorders Review Group systematic review of randomized trials. Am J Gastroenterology. 2009; 104(1):235-41. 
21. Miehlke S, Madisch A, Karimi D, Wonschik S, Kuhlisch E, Beckmann R, et al. Budesonide is effective in treating lymphocytic colitis: a randomized doubleblind placebo: controlled study. Gastroenterology. 2009; 136(7):2092-100.

22. Pardi DS, Loftus EV, Tremaine WJ, Sandborn WJ. A randomized doubleblind, placebo controlled trial of budesonide for the treatment of active lymphocytic colitis. Gastroenterology. 2009; 136(5 suppl 1):A519-20.

23. Bonderup OK, Hansen JB, Teglbjaerg PS, Chrustensen LA. Fallingborg JF. Long-term budesonide treatment of collagenous colitis: a randomised, double-blind, placebo-controlled trial. Gut. 2009; 58(1):68-72.

24. Miehlke S, Madisch A, Bethke B, Morgner A, Kuhlisch E, Henker C, et al. Oral budesonide for maintenance treatment of collagenous colitis: a randomized, double-blind, placebo-controlled trial. Gastroenterology. 2008; 135(5):1510-6.

25. Stewart MJ, Seow CH, Storr MA. Prednisolone and budesonide for shortand long-term treatment of microscopic colitis: systematic review and metaanalysis. Clin Gastroenterol Hepatol. 2011; 9(10):881-90.

26. Gentile NM, Abdalla AA, Khanna S, Smyrk TC, Tremaine WJ, Faubion WA, et al. Outcomes of patients with microscopic colitis treated with corticosteroids: a population-based study. Am J Gastroenterol. 2013; 108(2):256-9.

27. Olesen M, Eriksson S, Bohr J, Järnerot G, Tysk C. Lymphocytic colitis: a retrospective clinical study of 199 Swedish patients. Gut. 2004; 53(4):536-41.

28. Bohr J, Tysk C, Eriksson S, Abrahamsson H, Järnerot G. Collagenous colitis: a retrospective study of clinical presentation and treatment in 163 patients. Gut. 1996; 39(6):846-51
29. Pardi DS, Ramnath VR, Loftus EV, Tremaine WJ, Sandborn WJ. Lymphocytic colitis: clinical features, treatment, and outcomes. Am J Gastroenterol. 2002 97(11):2829-33.

30. Munck LK, Kieldsen J, Philipsen E, Fischer Hansen B. Incomplete remission with short-term prednisolone treatment in collagenous colitis: a randomized study. Scand J Gastroenterol. 2003; 38(6):606-10.

31. Chande N, MacDonald JK, McDonald JWD. Interventions for treating lymphocytic colitis. Cochrane Database Syst Rev. 2008; 16(2):CD006096.

32. Tangri V, Chande N. Microscopic colitis: a update. J Clin Gastroenterol. 2009; 43(4):293-6.

33. Calabrese C, Fabbri A, Areni A, Scialpi C, Di Febo G. Mesalazine with or without cholestyramine in the treatment of microscopic colitis: randomized controlled trial. J Gastroenterol Hepatol. 2009; 22(6):809-14.

34. Wildt S, Munck LK, Vinter-Jensen L, Fischer Hansen B, Nordgaard-Lassen I, Christensen S, et al. Probiotic treatment of collagenous colitis: a randomized, double-blind, placebo-controlled trial with Lactobacillus acidophilusand Bifidobacterium animalis subsp. Lactis. Inflamm Bowel Dis. 2006; 12(5):395-401.

35. Goff JS, Barnett JL, Pelke T, Appelman HD. Collagenous colitis: histopathology and clinical course. Am J Gastroenterol. 1997; 92(1):57-60.

36. Bonner GF, Petras RE, Cheong DM, Grewal ID, Breno S, Ruderman WB Short- and long-term follow-up of treatment for lymphocytic and collagenous colitis. Inflamm Bowel Dis. 2000; 6(2):85-91. 